\title{
Ontological and socio-cultural foundations of inter-generated discourse
}

\author{
Natalya Isakova $^{1,}{ }^{*}$, Grigory Nikitin $^{1}$, and Elena Yakovleva $^{1}$ \\ ${ }^{1}$ Kuban State Agrarian University named after I.T. Trubilin, 350044, Krasnodar, Russia
}

\begin{abstract}
The article is devoted to understanding the problems of intergenerational discourse and its transformation in ontological and sociocultural reality. The paper substantiates the need to maintain the mechanism of accumulation and reproduction of the experience of ancestors. It is shown that the violation of the knowledge transfer and traditions leads to the distortion or disappearance of universal cultural codes. The characteristic features of the culturological, psychological and demographic approaches are analyzed, the combination of which allows a more thorough study of the problem posed: to show the influence of historical and socio-cultural transformations on the characteristics of interaction between generations, to determine the form of transfer and assimilation of experience within the family, to demonstrate the socially significant consequences of the demographic revolution. The authors note the importance of maintaining communication between generations, which is a necessary condition for the further development and functioning of society.
\end{abstract}

\section{Introduction}

Culture, in the broad sense of the word, including all the facets of a person's material, spiritual and social life, is that aspect of ontological reality in which the translation of human self-expression various forms is realized, the skills, abilities and values are accumulated by society, and the ways of their transmission from one generation to another are reproduced. Based on the position that "communication is an ontological characteristic of a person" [1, p. 15], and it is impossible in a confined space or with the exception of any of its constituent parts, it becomes obvious that the transformation of communication methods and the loss of common meanings between representatives of different ages is, on the one hand, a universal phenomenon of human culture, and on the other hand is an urgent problem of our time in the field of broadcasting and communication, requiring versatile and in-depth study. The study of cultural heritage various methods transfer within the framework of an interdisciplinary approach allows us to highlight the important role of intergenerational interaction in the transmission and development of life experience and cultural codes. The study of these processes and their transformation in the socio-cultural space and historical time is an urgent problem that allows us to detect those metamorphoses

* Corresponding author: natalya-isakova@,bk.ru 
in the structure of modern reality that contribute to the destruction of the integrity and interconnection between generations. The universality of the intergenerational communication phenomenon, its complexity, and dependence on the historical and social dynamics of public sentiments, necessitate further study of this problem.

\section{Research area and objectives}

The problem of intergenerational discourse and cultural communication has been widely studied in philosophy, cultural studies, ethnography and anthropology, in various areas of clinical psychology and psychotherapy (K. Levy-Strauss, K., Jaspers, A. Adler, C. Jung, Z. Freud, E. Fromm, E. Byrne, J. L. Moreno, F. Dalto, N. Abraham, M. Terek, I. BuzormeniNagy, A. A. Schutzenberger, M. Bowen, F. Juttner, M. Mead, F. Boas, B. Malinovsky, N. Peseshkian, N. McMaster, E.G. Eidemiller, V.V.Yustitskis, A.I. Zakharov, E.V. Kuftyak, M.A. Sizova and others). Demographic studies only indirectly affect this issue, but, nevertheless, are an excellent empirical source for studying this problem (Kapitsa S.P., A.G. Vishnevsky, S.P. Kurdyumov, G.G. Malinetskiy, F. Brodel, P.J. Buchanan et al.) An interdisciplinary approach involves a wider coverage of existing concepts and shows that the patterns of human society development cannot be reduced only to biological, economic or socio-cultural patterns.

As the initial task of the study, it is supposed to identify historical and socio-cultural changes in the field of translation and appropriation of experience, to conduct a cultural analysis that gives a clear idea of the interaction evolution methods between generations. Attraction of developments devoted to the problem of the demographic revolution allows us to understand the essence of time compaction and compare it with large-scale changes in human society, with the destruction of human social instincts that have been formed over many generations. It seems important to demonstrate the psychological approach to the study of intergenerational relationships, the forms of experience transfer within the family system and the features of its functioning.

\section{Discussion}

One of the most important results of communication and interconnection of generations is the creation of such traditional structure in which certain models of behavior are realized, transmitted by the ancestors to their descendants. Any tradition contains a local complex of ideas, values, semantic ideas, archetypes that are constantly relayed, thereby maintaining the vitality of this tradition. The spiritual and cultural evolution of mankind is impossible without the emergence of new traditions, values, social attitudes, but also without maintaining continuity in the sphere of culture and life, without accepting the memory and experience of ancestors. And if the mechanism of accumulation and reproduction of experience is violated, then there is a break in intergenerational relationships, distortion, and sometimes the disappearance of universal cultural codes. The nature of the relationship predominantly becomes contextualized and situational. This occurs when the contact of different generations experience causes a certain resonance, rejection and discrimination by the descendants of the culture and traditions of their ancestors, which, depending on situational factors, become either unclaimed and outdated or misunderstood.

This phenomenon of human existence is not a modern problem and arose with the advent of human culture and civilization. At a certain stage of communication, people from different generations and age groups lose their common ground - certain worldview constants that allow you to "glue" multidimensional reality and form a productive sociocultural translation and cultural configuration. They differ in the style of thinking, attitudes, 
beliefs and, accordingly, their value orientations and guidelines are in different ontological planes.

Ever since the time of Socrates and Hesiod, there have been regrets about the bad manners and intolerance of young people, about their frivolity and lack of respect for the elderly. Centuries and millennia pass, society changes, new cultural meanings appear, the very structure and fullness of being is transformed, the methods of communication acquire new features and properties, but the conflict of generations remains unresolved. Therefore, the problem of "fathers and children", perceived, on the one hand, as a stage of maturation and transformation of an individual, as part of cultural and social evolution process of mankind, and, on the other hand, as an integral part of human life, unfolded in social time and cultural space, still relevant. It is caused by the features of a particular historical process, the growth and development of human consciousness, its culture and the peculiarity of knowledge transfer system from generation to generation.

\section{Knowledge transfer model in different types of culture}

An interesting typology of culture, filled with empirical research and relevant to modern cultural reality, was proposed by the American anthropologist and culturologist Margaret Mead [5]. She classified culture as an evolution of how generations interact in translating social and cultural experiences. Having set off to explore Polynesian society in 1925, she collected colossal empirical material that allowed her to create her own typology of cultures, in which she revealed the characteristics of the generations interaction in different cultures, described their inherent conflicts, showed the influence of ancestors on the consciousness of young people in different types of culture, and characterized trends and prospects for the development of youth consciousness in the middle of the XX century [5, p. 322-361].

For the researcher, history is a combination of three types of cultures: post-figurative, co-figurative, and pre-figurative. The first type is characteristic of archaic traditional cultures, where there is continuity and dependence on older generations, where children learn from their ancestors, where the past is a diagram of the future, in which the identity and originality of the people culture are preserved [5, p. 322-342].

In the configurative culture, the older generation still dominates, determining the style of configuration and behavior of young people, but at the same time, the influence of contemporaries and a new style of behavior, different from the behavior of parents and ancestors, are allowed. The appearance of the configuration, according to M. Mead, is caused by the crisis of the post-figurative system, which may be caused by a catastrophe that destroyed the majority of the older generation, relocation to a new country, conquest or conversion to a new faith, or, as a result, the emergence of new forms of technology unknown to elders. The experience of the elderly is no longer so valuable, and young people are developing a new model of culture. Intergenerational interaction is becoming more complex, sometimes conflicting. However, as the author notes, the configuration in culture is quite superficial in nature, does not affect the deeper layers of culture and does not change the fundamental existential attitudes of reality - the core of culture remains until the need arises [5, p. 342-355].

Pre-figurative culture is a completely new model that creates unusual and previously unknown mechanisms for changing and transmitting culture, announces new human capabilities. M. Mead believes that there is a certain migration in time. The rapidly changing reality makes the future unknown and unpredictable, forcing a person to mobilize hidden resources and strengthen his life and spiritual forces. [5, p. 357-359].

Currently, pre-figuration as a form of culture and a model for the transfer of knowledge is no less relevant than in the first half of the $\mathrm{XX}$ century. In the conditions of an 
irreversibly changing world, a new way of intergenerational interaction has developed - the older generation learns from its children, who have become carriers and creators of a new, incomprehensible adult reality. The older generation may be, in the words of M. Mead, "immigrants in time" if they cannot learn the experience of the new generation and new life [5, p. 360].

\section{Generation disunity in the information society}

Similar phenomena are observed, first of all, in countries with a high level of industrialization, rapid growth of information technologies and their growing influence on the mass consciousness [19, p. 661-663]. Today, young people are literally imposed a radical cultural gap with previous generations [11, p. 21]. The modern socio-cultural, spiritual and even economic spheres are no longer based on old traditions - they ignore them or even deny them. Literally in one generation, ideas, values, and world outlook constants are radically changing. Moreover, not the changes themselves, but the speed with which they occur creates such a deep gap between generations. And this gap between young people and their ancestors, on the one hand, is a completely natural socio-cultural phenomenon, and on the other hand, it is actively exploited on a mass scale, creating bizarre and artificial forms, a process.

For example, a modern, actively propagated trend is the popularization of the superiority of youth over mature and elderly people (ageism), the development of a negative attitude towards them. The attitude to work and professional experience of the older generation is fundamentally changing: young people strive for independence and a free schedule, quickly adapt to new economic realities, not being tied to one workplace and profession, easily change jobs, giving priority to project activities rather than stable work with a clearly defined schedule and working conditions. These processes affect not only the Big History and human society as a whole, but also the individual person, changing the deeply personal, existential aspects of his existence, his attitude to work and selfrealization, to life and death, to love, to family ties and traditional values.

\section{Acceleration of historical time and demographic transition}

Today, this gap between generations is turning into an abyss - social dramas, new ways of communication, the very structure of socio-cultural reality is becoming more complex and more significant, undergoing transformation in all aspects of its existence. Time accelerates and contracts, information, and, consequently, experience, knowledge in many areas quickly become obsolete.

Outstanding physicist and popularizer of science S.P. Kapitsa noted that the higher the complexity of the system, the more people live on earth, the faster time passes [4]. His comprehensive studies of history and the foreseeable future of mankind showed that in each of the historical eras, from the Paleolithic to the latest history, the population was about eight billion people, thereby forming pieces of history that were identical in content (rather than in duration) [4, p. 72]. This amazing fact demonstrates that in just half a century, ten billion people "pass" the earth, that is, the "historical era has shrunk" to one generation. Today, the compression of historical time has come, according to S.P. Kapitsa, to the limit, it is limited by the duration of one generation, and the dying of traditions and the breaking of communication between generations is a natural consequence of the history acceleration [4, p. 161-162]. Each generation, according to the author, lives in its own era and the legacy of previous generations may not be useful to him, because morality, social attitudes and values were adapted to the former, unchanged regime of development for a long time, and 
now everything is changing. This development takes place in an open system and selfaccelerates, culminating in a demographic revolution that subjugates all the processes of human society [4, p. 88-89]. In such historical transitions, the scientist notes, the scale of social changes that affect a person's life becomes so significant that neither an individual, nor society as a whole, have time to adapt to the new world order. The change in the growth rate of the system, when each stage in the history of civilizations is characterized by a shorter life cycle, is reflected in the phenomena of culture and consciousness, accompanied by a crisis of values and moral standards of society, which have been formed over the centuries, and the acceleration of the historical progress rate. There is a change in the very paradigm of human growth and the meaning of its development [3, p. 28-36; 4, p. 84-86].

\section{Intergenerational communication in the family system}

Discourse, communication in general, ways of transferring experience and significant cultural codes from ancestors to descendants still remain an important part of human society. Along with the external manifestations of the intergenerational gap, there are internal, most often unconscious mechanisms of the family system safety and the features of its functioning. An analysis of the psychological conditionality of intergenerational continuity shows that the form of experience transfer within the family forms a special type of human interaction with the outside world and affects the choice of ways to overcome difficulties, its values, norms, attitudes and rules. The way the ancestors pass on their experience and their assimilation by descendants is a two-way process, depending not only on how valuable and significant the experience is for descendants, but also on how it is presented and evaluated by the ancestors themselves, and on what mechanisms (unconscious or conscious) are the basis of the translation of experience and communication [9, p. 6-20].

As in the culturological approach, psychologists distinguish several typologies that characterize the relationship between generations in the family and close people. They distinguish "preserving continuity", in which there is a two-way exchange of experience between generations and a conscious heritage, "one-way transmission", where the transfer of experience goes only from ancestors to descendants and there is no awareness of inheritance and, "broken continuity", which has a distinctive feature in the weak severity of the experience transfer from ancestors to descendants and awareness in the inheritance of experience [9, p. 8-20].

An interesting aspect of intergenerational communication is also emphasized - despite the apparent gap between generations, in fact, there is an inseparable unity between ancestors and descendants. A family is a "social atom" in which there is a strong emotional connection and (consciously or unconsciously) information is transferred from one generation to another (J. Moreno) [6], a complex interweaving of family stories unfolds, an unconscious repetition of experience (often dramatic) (A. Shutzenberger) $[14 ; 15]$, certain forms of behavior (generic unconscious) are transmitted and fixed, an unaccountable choice of a profession, spouse, friends and methods of self-determination are carried out, in which a person is "not free", since the whole race is represented in his person (L. Sondi) [10] . A deep relationship is manifested not only in the family sphere, but also continues to remain unchanged for many centuries and generations in the ethical and legal system (for example, principles such as justice, inevitability, guilt in the framework of the appointment of legal liability measures) [20, p. 825-839].

In general, in many works summarizing clinical and statistical experience, the idea of the importance of understanding and comprehension the experience of ancestors is traced as a necessary condition for further constructive development of a person. 


\section{Conclusion}

Having outlined only a few reasons for the intergenerational discourse in the field of translation of socio-cultural experience, it can be noted that their combination forms the layer of human life in which historically determined values and ideals of human society are realized, methods of accumulation and transfer of experience that are unique for each historical era, new methods communications. Intergenerational communication is a prerequisite for the normal development and functioning of society, for further progress and development, as well as for the creation of a unique and viable sphere of human life in which the most important function responsible for the survival, preservation and evolution of human civilization could be realized - the acceptance of experience previous generations and its integration in the individual personal experience of descendants.

Human being is multidimensional and unfolds in space and time limited by human life. During this short period of time, by historical standards, a person must have time to realize not only a biological species, but also realize spiritual and conscious growth, create his own unique inner world, manage to "plant" and "taste" the fruits of his activity, and actualize himself in society, history and culture. The events that we observe today in world and Russian reality - the destruction of the institution of the family or the rejection of marriage in general, the demographic imbalance of the population (age, gender, territorial, etc.), the rapid obsolescence and depreciation of knowledge, information, experience of previous generations, actualizes the problem of intergenerational discourse in a new way and requires its further study.

\section{References}

1. S.S. Avanesov, Anthropology today: correction of basic guidelines, Person, 3, 5-33 (2017).

2. A. Adler, Parenting. The interaction of the sexes, (Phoenix, Rostov-on-Don, 1998).

3. S.N. Grinchenko, The evolution of the pace of human life and the development of mankind,Man No, 5, 28-36 (2014).

4. S. Kapitsa, Growth paradoxes: The laws of global development of mankind, (Alpina non-fiction, Moscow, 2013).

5. M. Mead, Culture and the world of childhood. Selected works (The main edition of the eastern literature of the publishing house "Science", Moscow, 1988).

6. J. Moreno, Psychodrama (April: Eksmo, Moscow, 2001).

7. N. Peseshkian, Positive family psychotherapy: the family as a therapist: trans. with him (March, Moscow, 1996).

8. M.V. Saporovskaya, The theory and practice of intergenerational communication research in a family context, Psychological Research, 1 (9) 2010.

9. M.A. Sizova, Interrelation of intergenerational relations and family functionality: abstract of thesis (Kostroma State University named after N.A. Nekrasov, Kostroma, 2012).

10. A.V. Tikhomirov, Fate analysis (Three squares, Moscow, 2007).

11. Social and humanitarian technologies: human development resources or objects of manipulation, Man, 6, 23-34 (2011).

12. Z. Freud, Totem and taboo, "I" and "It": Works of different years: trans. with him, Merani, 1, 193-350 (1991). 
13. E. Fromm, Anatomy of human destructiveness (Moscow,1994).

14. A.A. Shutzenberger, Psychogenesis: How to heal family wounds and find yourself (Psychotherapy, Moscow, 2010).

15. A.A. Shutzenberger, Syndrome of ancestors. Transgenerative relationships, family secrets, anniversary syndrome, transmission of injuries and the practical use of genosociograms (Publishing House of the Institute of Psychotherapy, Moscow, 2005).

16. K.G. Jung, Archetype and Symbol: Per. with him (Renaissance, Moscow, 1991).

17. K.G. Jung, Marriage as a psychological attitude (Conflicts of the child's soul, Moscow, 1995).

18. A.V. Tikhomirova, Fate analysis in the conclusions (Publishing House Ural. University, Yekaterinburg, 2002).

19. M.I. Danilova, G.M. Nikitin, The Phenomenon of "Virtualization" of the World in Modern Society, The Phenomenon of "Virtualization" of the World in Modern Society, Astra Salvensis, 12, 661-663 (2018).

20. S.V. Potapenko, E.B. Luparev, N.Y. Embulayeva, E.V. Epifanova, L.S. Embulaeva, T.E. Pavlisova, The moral foundations of legal liability (criminal, administrative, tort), Astra Salvensis,. 2017, 825-839 (2017). 